a Court of Law and might even involve the psychiatrist who repeats them in a libel action. Freud himself had later to admit that the accusations his female patients made against their fathers which he at first believed were the product of their imagination and distorted memory. Every policeman knows how readily people under some emotional strain may accuse themselves of murder or serious crimes they have never committed.

However, such subterfuges and treating the legal profession with their own medicine should not be necessary, nor need we wait, as Dr. Spencer suggests, till some psychiatrist is prepared to go to prison. I am sure, Sir, that the whole profession and the common man in the street would wholeheartedly stand behind the B.M.A. or any medical M.P. who would propose to bring the law for the physician (and incidentally the priest) in line with the solicitor, whose communications with his client are legally recognized as privileged.I am, etc.,

Leicester.

K. A. Graf.

SIR,-May I congratulate Dr. Seymour J. G. Spencer (8 August, p. 382) on his letter concerning confidential information from patients and the fact that it is not privileged in law ? His remarks, I am sure, apply to all doctors, not only to psychiatrists. I recently refused to hand my records of a patient to the solicitor, who subsequently obtained a sub poena for their surrender. Apparently anyone in the legal profession can do this without its necessity being questioned.

I wrote to the B.M.A. with a copy to my M.P. complaining of this, and the unsatisfactory reply I received was to the effect that it was the law and we must make the best of it, and in particular the main consideration in giving information should be the agreement of the patient. How can the patient know what he is agreeing to when he does not know what is written in his doctor's notes? The whole affair is a confidence trick by Members of Parliament on the general public. They urge the public to "tell your doctor," but do not tell them that they have so made the law that once given they can extract these confidences forcibly. I would at least like to see a suitably worded notice in every waitingroom giving this information. Of course, Dr. Spencer is right, and it can only harm the public.

The B.M.A. should know that this law is bad and stop playing at being amateur politicians and expedient, and fight. The best way to fight in my opinion is to pay a good salary to a man with the right character and qualifications (not medical) who could outmatch the politicians in deceit and ruthlessness.-I am, etc.,

Stafford.

\section{G. Theophilus.}

\section{Modern Drug Therapy : A Hindrance to Early Cancer Diagnosis?}

SIR,-May I ask for the courtesy of your columns to draw attention to a course of action that threatens to become a danger in gynaecological practice? This is the use of certain forms of medication which may tempt the doctor to omit the physical examination of his patient which he would otherwise regard as necessary. The following two recent cases illustrate my point; similar events can doubtless be related by other gynaecologists.

\section{Case 1.-Advanced Carcinoma of the Corpus} Uteri

A nullipara, aged 50, highly intelligent, had "always had heavy periods." Menstruation had recently occurred at more frequent intervals, and for nine months there had been a constant slight blood loss. Her doctor had been early consulted and had prescribed a hormone preparation credited with the power to restore a normal menstrual habit. Despite its use the bleeding continued. A change in the patient's domicile resulted in her reporting to hospital: an advanced carcinoma of the body of the uterus was then found.

Case 2.-Advanced Carcinoma of the Cervix Uteri

An intelligent woman, 40 years of age and mother cf two children, had noticed an irregular bleeding for three months; in particular, there was a slight but repeated post-coital bleeding. She was at that time on the "contraceptive pill." Her doctor, censidering that the symptoms could be sufficiently explained by the "break-through bleeding" which is sometimes seen during this course of medication, made no pelvic examination but instead wasted time in changing from one form of "pill" to another. When, eventually, the patient reported to hospital a large extroverting carcinoma of the cervix was found. Incidentally, no cervical smear had been obtained nor pelvic examination made before the contraceptive medication was started.

These histories, different in detail, are alike in their consequences. In both there was an apparent excuse to dispense with customary pelvic examination; and in both the treatment so urgently needed was grievously delayed. Here, I reproach the drug manufacturers who (with a few laudable exceptions) do not in their explanatory pamphlets sufficiently stress the need for adequate physical examination of the patient before starting a course of medication intended in one group of cases to correct an abnormal menstrual rhythm, and in the other to modify the normal ovulatory cycle. We who are teachers are also at fault. We do indeed explain to our students that irregular uterine bleeding calls for a careful pelvic examination; but it seems that we do not shout our warning loud or long enough. Every women who has irregular or post-menopausal bleeding must have a pelvic examination. This should include smears for cytological examination, and, in the absence of obvious cause for the haemorrhage, a uterine curettage.I am, etc.,

$$
\begin{aligned}
& \text { Nuffield Dept. of Obstetrics } \\
& \text { and Gynaecology, } \\
& \text { The Radclife Infirmary, } \\
& \text { Oxford. }
\end{aligned}
$$

\section{J. Chassar Moir.}

\section{Maternal Syndrome in Hydrops Foetalis}

SIR,-It is a pleasure to be able to agree with Mr. G. J. Sophian (1 August, p. 312) when he comments on your leading article of 4 July entitled "Maternal Syndrome in Hydrops Foetalis," saying that this condition is pre-eclampsia, and not a new disease. The mere fact that it has only been established in a series of papers since Professor Kloosterman, of Amsterdam, first drew attention to it in $1947^{1}$ does not make the association of pre-eclampsia and hydrops foetalis any less real. Not only are the signs of pre-eclampsia present but the pathological changes typical of eclampsia have been recorded at necropsy."

Unfortunately, pleasurable agreement ceases when Mr. Sophian reverts after his first paragraph to his often-repeated exercise of marshalling a selection of observations to support his utero-renal reflex theory of the aetiology of pre-eclampsia. One would be only too happy to be able to accept his theory if it fitted even approximately the known facts, but unfortunately the evidence is that excessive uterine distension due to simple, uncomplicated hydramnios without quantitative or qualitative placental abnormality is not associated with a significant increase in the incidence of the pre-eclamptic syndrome. ${ }^{23}$ We must therefore continue the search for more complex mechanisms in the causation of pre-eclampsia.

Further discussion would not be profitable here, but it might be helpful to reiterate that pre-eclampsia is merely a hypertensive syndrome of pregnancy and that it is no more appropriate to look for a unique aetiology than in the case of hypertension in the non-pregnant subject. There is probably much to be said for following Theobald's suggestion and talking merely of hypertension, oedema, and proteinuria.-I am, etc.,

Department of Obstetrics JAMES S. ScotT.

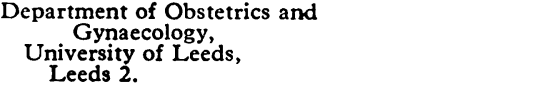

REFERENCES

Kloosterman, G. J., Over de Polyletaliteit in Verband met het Vlokkenstroma en de Rhesu factor, 1947. Grafische Kunstinrichting Rotting,
Hilversum.

Scott, J. S., J. Obstet. Gynaec. Brit. Emp., 1958,

65, 689.

\section{Is Arterial Puncture Dangerous ?}

SIR,-I might be able to answer Professor W. W. Mushin's question (1 August, p. 310) in regard to brachial-artery punctures under local analgesia for the purpose of blood-gas analysis. I have done over 1,000 to date without incident. One brachial artery was punctured six times during the course of a difficult and severe chest infection and at necropsy it was impossible to be sure where the punctures had been made. One of the most important considerations in my work, a long-term study, has been the co-operation of my patients, and only one out of over 200 has objected to an arterial puncture a second time.

It can be used as readily as venepuncture for pure research purposes. There are, however, important technical consideration. Have a syringe with a freely moving barrel and a very sharp, preferably new, needle. Infiltrate with local down to the artery wall to prevent spasm. Use a No. 1 needle and advance the tip until the arterial pulsation can be felt. Then push gently into the artery. If blood does not rise at once into the syringe the artery may have gone into spasm, and pull gently on the barrel. Do not prod around. If unsuccessful try the other arm.

The most important part of the operation is to have an alert nurse or assistant who can apply firm pressure to the puncture for about three minutes once the needle has been with- 